\title{
Chronic pancreatitis caused by a swallowed orthodontic device
}

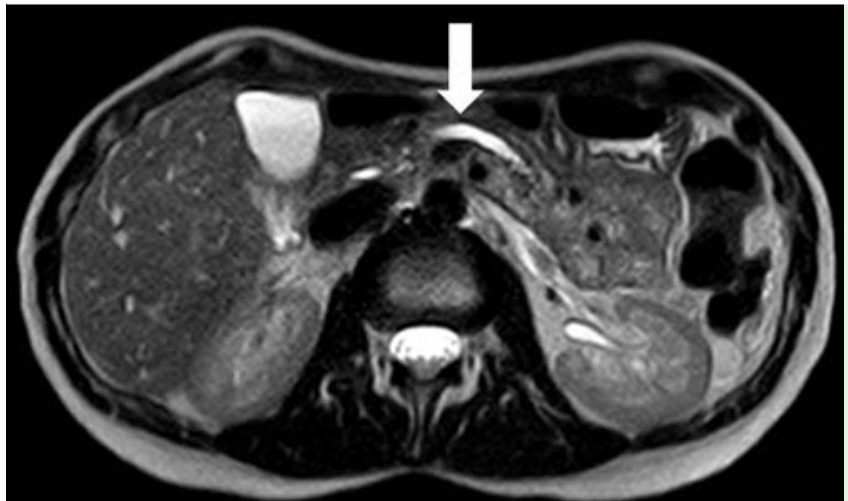

Fig. 1 Magnetic resonance imaging (MRI) scan showing a dilated pancreatic duct (arrow) in a 37-year-old woman with epigastric pain recurring episodically over a period of years.

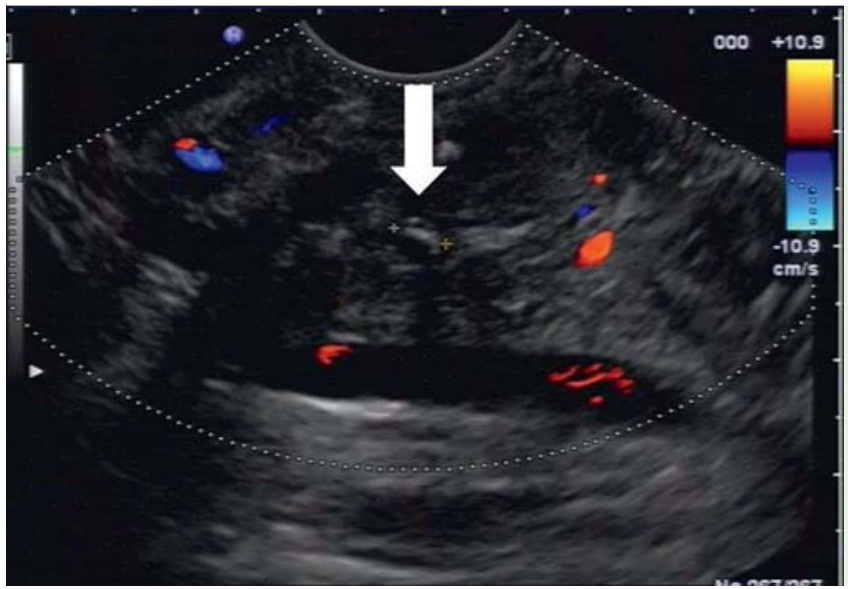

Fig. 3 Endosonographic image of the head of the pancreas, with a small area of calcification (arrow), a sign of a chronic inflammation.
A 37-year-old woman was admitted to our hospital for endosonography because of a pancreatic duct dilatation. Originally, this dilatation had been noted during magnetic resonance imaging (MRI) ( $\bullet$ Fig. 1 ) for epigastric pain recurring episodically over a period of years. Endoscopically, we found a metallic object trapped inside the papilla Vateri ( Fig.2). Endosonography revealed calcifications in the pancreatic head ( $\bullet$ Fig. 3 ) suggesting chronic pancreatitis. The metallic object was removed endoscopically with a snare and was found to be a Kobayashi ligature ( Fig.4). This device is used by orthodontists and is fixed by drilling it into dental braces. Our patient reported that a dental brace had been implanted at the age of 12 . The extracted ligature was not drilled, substantiating the suspicion that it had been ingested before fixation to the brace, and probably swallowed during the implantation procedure. After extraction of the ligature from the papilla, our patient's clinical symptoms improved remarkably. In summary, our patient suffered from chronic pancreatitis caused by obstruction of the papilla Vateri by an orthodontic device implanted years earlier.

Chronic pancreatitis is characterized by progressive fibrotic destruction of the pancreatic secretory parenchyma [1]. There are only a few reports on obstruction of the papilla Vateri by an ingested foreign body resulting in acute, but not chronic, pancreatitis [2,3]. Ingestion of dental bodies is quite commonly reported [4], although mostly after implantation; however we only found one review reporting on devices ingested during dental treatment [5]. That publication mainly reported on swallowed reamers which were removed within the first month after implantation.

Our study reports a case where a metallic device resided for years obstructing the papilla Vateri and resulting in chronic

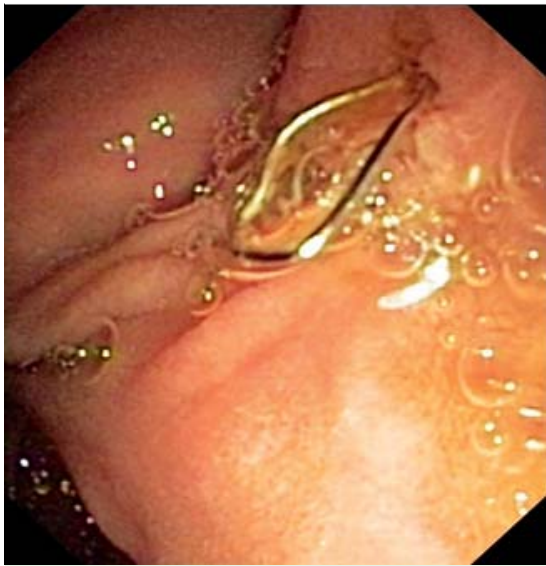

Fig.2 Endoscopy with a side-view duodenoscope. A metallic object is present lodged inside the papilla Vateri.

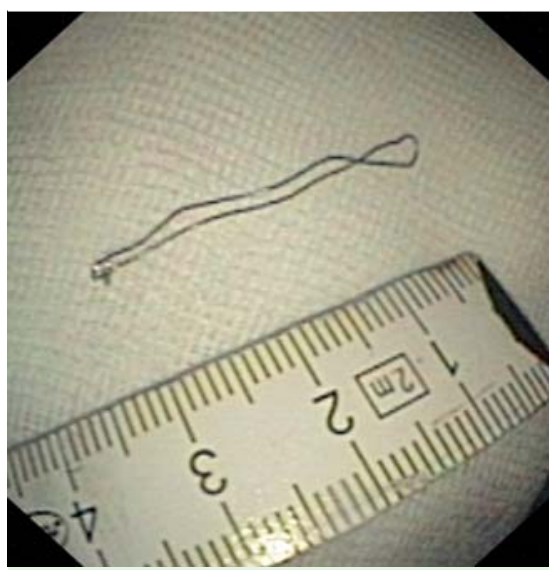

Fig.4 The metallic object, a Kobayashi ligature, after extraction endoscopically with a snare.

pancreatitis. Moreover, it emphasizes that dental devices may be swallowed not only after an implantation procedure but even during it. If ingestion remains undetected, it may result in chronic complications.

Endoscopy_UCTN_Code_CCL_1AZ_2AG

\section{Competing interests: None}

\section{Maximilian Tiller, Wolfgang Schepp, Felix Gundling, Jochen Tuerck}

Department of Gastroenterology, Hepatology and Gastrointestinal Oncology, Bogenhausen Academic Teaching Hospital, Munich Municipal Hospital Trust, Munich, Germany 


\section{References}

1 Brock C, Nielsen LM, Lelic D et al. Pathophysiology of chronic pancreatitis. World J Gastroenterol 2013; 19: 7231 - 7240

2 Casas J, Suarez G, Jimenez S et al. Acute necrotizing pancreatitis by a foreign body. First worldwide report secondary to a match impactation. Rev Gastroenterol Peru 2010; 30: $216-219$

3 Imamura $H$, Konagaya $T$, Hashimoto $T$ et al Acute pancreatitis and cholangitis: a complication caused by a migrated gastrostomy tube. World J Gastroenterol 2007; 13 : $5285-5287$

4 Gundling F, Seidl H, Stark T et al. Management of impacted foreign bodies in the upper gastrointestinal tract in adult patients - results of a retrospective case series. Z Gastroenterol 2012; 50: 1287-1291

5 Tamura N, Nakajima T, Matsumoto $S$ et al. Foreign bodies of dental origin in the air and food passages. Int J Oral Maxillofac Surg 1986; 15: 739-751

\section{Bibliography}

Dol http://dx.doi.org/

10.1055/s-0034-1390866

Endoscopy 2014; 46: E667-E668

(c) Georg Thieme Verlag KG

Stuttgart · New York

ISSN 0013-726X

\section{Corresponding author}

\section{Maximilian Tiller}

Klinik für Gastroenterologie, Hepatologie und Gastroenterologische Onkologie

Klinikum Bogenhausen

Städtisches Klinikum München GmbH

Englschalkingerstr. 77

81925 Munich

Germany

Fax: +49-89-92702486

Gastroenterologie.kb@klinikum-muenchen.de 